\title{
The relationship between smartphone using style and sleep quality and psychiatric symptoms among a foundation university students
}

\author{
Emin Erinç Yücel ${ }^{1 \oplus,}$ Barış Önen Ünsalver \\ ${ }^{1}$ Department of Psychology, Üsküdar University, Clinical Psychology Master's Program, İstanbul, Turkey \\ ${ }^{2}$ Department of Psychology, Üsküdar University, Faculty of Humanities and Social Sciences, Istanbul, Turkey
}

\begin{abstract}
Objectives: We aimed to measure problematic smartphone use frequency and it's association with sleep problems and psychiatric symptoms in a sample of university students.

Methods: The data in the study was collected by using a sociodemographic data form, the Smartphone Addiction Scale (SAS), the Pittsburgh Sleep Quality Index (PSQI), the Epworth Sleepiness Scale (ESS) and the Brief Symptom Inventory (BSI).

Results: Based on the SAS median score, the participants were divided into two groups as the low-level smartphone use (SAS score $<79$ ) and the high-level smartphone use (SAS score > 79) groups. In the highlevel smartphone use group, general sleep quality was lower, sleep latency was longer, scores of sleep disorder and daytime dysfunction were higher as measured by PSQI and the BSI scores were higher $(p<0.001)$. As a result of the study, it was observed that, as smartphone use increased and became problematic, sleep quality decreased, and daytime dysfunction and psychiatric symptoms increased. SAS scores were positively correlated with both PSQI and ESS scores. SAS score was found as a predictor of PSQI scores in the regression analysis. Conclusions: This study shows that the relationship between problematic smartphone use and decreased sleep quality and increased psychiatric symptomatology in university students is still an important public health issue. Responsible and mindfull use of smartphones by the students throughout the day may provide a positive effect on their sleep.
\end{abstract}

Keywords: Smartphone addiction, behavioral addiction, sleep

n recent years smartphones are being used for various purposes such as contacting people every time and everywhere, connecting to the internet, conducting banking operations, shopping, taking care of state-related processes, playing games and listening to music. As the usage of smartphones has become widespread, it is observed that some people have started to show a problematic form of using smartphones that may result in psychological, physiological and social problems. While the term "smartphone addiction" was proposed as a type of behavioral addiction [1], more recent articles suggested that, instead of the term addiction, naming this issue as 'problematic smartphone use' would be more appropriate $[2,3]$. Whether it is called 'smartphone addiction' or 'problematic smartphone use', it may be argued that it has become a significant

How to cite this article: Yücel EE, Önen Ünsalver B. The relationship between smartphone using style and sleep quality and psychiatric symptoms among a foundation university students. Eur Res J 2020;6(6):569-579. DOI: 10.18621/eurj.538377

Address for correspondence: Barlş Önen Ünsalver, MD., Associate Professor of Psychiatry, Üsküdar University, Faculty of Humanities and Social Sciences, Department of Psychology, Altunizade Mahallesi, Haluk Türksoy Sk. No:14, 34662 Üsküdar, İstanbul, Turkey

E-mail: baris.unsalver@uskudar.edu.tr,Tel: +902166330633,Fax:+902166341250 
public health problem that is increasingly prevalent all over the world [3].

Smartphones may be functional or dysfunctional tools of coping with stress depending on the form of usage. While the stress-reducing applications on the phone may be functional $[4,5]$, playing games or gambling for a long time, or, staying on social media without a purpose may not only increase the stress load on the person but also turn into a problematic behavior due to temporary feelings of relaxation provided by these practices. For example, a meta-analysis that discussed 39 independent studies reported that stress and anxiety increased alongside increase usage of smartphones [6].

Sleep is a vital and physiological state that makes our entire body ready again for the active daytime [7]. If the person feels vigilant, fit and ready for a new day after they wake up, it may be argued that they have good sleep quality. In addition to the quantitative aspects of sleep such as sleep latency and number of times of waking up in one night, sleep quality is also related to the subjective aspects of sleep such as its depth and restfulness [8]. People who do not sleep enough may experience problems such as fatigue, weariness, reduced attention, increased sensitivity that leads to pain, irritability, illogical thoughts, chronic headache, loss of motivation, hallucinatory perceptions, loss of appetite, immune dysfunctions, increased cardiovascular risk, weight gain and metabolic problems $[9,10]$.

The factors that disrupt sleep among students include increased number of academic responsibilities, consumption of caffeine and alcohol, insufficient or incorrect physical activity, dietary habits and smartphone use [11-14]. A study that was carried out in Switzerland with 362 high-school students reported that the teenagers who had smartphones had delayed times of going to bed, they experienced more sleep problems in comparison to those that did not have smartphones, and they slept less in the weekends, which was related to depressive symptoms [15]. Demirci et al. [12] found that $39.8 \%$ of Turkish university students had high rates of smartphone use, $37.9 \%$ had low rates of smartphone use. They observed that depression and anxiety levels increased while sleep quality decreased in problematic smartphone users. Mohammadbeigi et al. [14] reported that $10.7 \%$ of 380 university students had problematic smartphone use, and problematic smartphone use disrupted sleep quality significantly [14]. Matar Boumosleh and Jaalouk's study [16] in Lebanon with 688 university students determined that $35 \%$ of the sample felt tired in daytime in relation to using smartphones until late hours at night, $38.1 \%$ had reduced sleep quality, and $35.8 \%$ slept less than four hours on multiple occasions due to smartphone use. Tao et al. [17] conducted a study with 4747 college students and found problematic smartphone use in $28.2 \%$ of the sample, as well as sleep problems in $9.8 \%$ by using PSQI. Accordingly, they did not find a significant relationship between problematic smartphone use and psychiatric diseases in those with good sleep quality. As a result, it was proposed that a good quality of sleep may be preventive against psychopathology development even in cases of problematic smartphone use [17]. It was reported that using smartphones at night was among the reasons of sleep problems also in 906 athlete students around the age of 19 who could be expected to have high quality of sleep as they are involved in regular physical activity [18]. A study that was carried out with 82 mid-level and high-level managers showed that using smartphones at night for jobrelated purposes affected their ability to focus on their job in daytime as a result of interruption of sleep at night [19]. A 1-year-long prospective study that was conducted with 4156 young adults revealed that excessive smartphone use resulted in higher stress loads, depressive symptoms and sleep disorders in comparison to the initial statuses [20]. A study which monitored 383 teenagers for 2 years reported that those who owned a smartphone experienced reductions in sleeping times [21]. All these studies suggest that there is an association between problematic smartphone use and sleep disorders. Given the high number of studies conducted on the subject, we thought people and especially university students must have become more aware of the consequences of smartphone use and that they might have started developing healthier ways of using their phones. Therefore, we wanted to measure problematic smartphone use frequency and it's association with sleep problems and psychiatric symptoms with a new sample of university students. We carried out a questionnaire study that investigated the relationship between the smartphone use characteristics of a group of university students and their sleep quality and psychiatric symptoms. 


\section{METHODS}

\section{Participants}

The sample of the study consisted of a total of 362 volunteer students including 242 women and 120 men in a foundation university.

\section{Measures}

The data in the study was collected by using a sociodemographic data form, the Smartphone Addiction Scale (SAS), the Pittsburgh Sleep Quality Index (PSQI), the Epworth Sleepiness Scale (ESS) and the Brief Symptom Inventory (BSI). Sociodemographic data form was developed by the researcher to collect information from the participants regarding their age, gender, marital status, class year, department and smartphone checking activity.

The Smartphone Addiction Scale (SAS) is a selfreport scale that measures smartphone addiction under six dimensions (daily-life-disturbance, positive anticipation, withdrawal, cyberspace-oriented relationship, overuse and tolerance) consisting of 33 6-point Likert-type items that was developed by Kwon et al. [1]. The test is valid and reliable in Turkish [22]. No cut-off point was determined for the scale. Kwon et al. [1], found the mean score of those who accepted that they had problematic smartphone use as $120.15 \pm$ 31.55. In the Turkish reliability and validity study, based on the median value of the sample, those with 72 points or above were considered to be high-level users, while those with 71 points or below were considered to be low-level users. Higher scores indicate more serious smartphone addiction.

Pittsburgh Sleep Quality Index (PSQI) is a selfreport scale developed by Buysse et al. [23] which measures the quality of life and provides information on the type and severity of sleep disorders for the previous month. The test is valid and reliable in Turkish [24]. The total index scores of 6-10 indicate poor sleep, while over 10 points indicate long-term sleep disorders.

Epworth Sleepiness Scale (ESS) is a self-report scale developed by Johns [25]. It questions the general sleepiness level of the individual. It is an 8-item scale and is valid and reliable in Turkish [26]. If the total score is higher than 5 , it suggests daytime sleepiness. Scores of 10 or higher may be considered as severe sleepiness.
Brief Symptom Inventory (BSI) is a scale composed of 53 items developed by Derogatis to catch psychiatric problems in various medical cases [27]. The inventory is valid and reliable for Turkish youth [28]. The scale has a 5-factor structure. These factors are: 'Anxiety', 'Depression', 'Negative Self', 'Somatization' and 'Hostility'.

\section{Procedures}

The questionnaire forms were distributed to the students of associate's, bachelor's and master's degrees in person in closed envelopes between the dates of 1 and 30 November 2017 by the first author.

\section{Statistical Analysis}

All statistical analyses were performed using SPSS v.18.0 (IBM Corp., Armonk, NY, USA). Descriptive statistics are presented as mean \pm standard deviation, median (25th-75th percentile), frequencies and percentages. Kolmogorov-Smirnov test was used to assess whether the continuous data fit normal distribution. Independent-samples t-test or Mann Whitney U test was used to compare continuous variables when appropriate. The categorical variables were compared with Pearson chi-squared test. Pearson's and Spearman's correlation tests were used to determine the strength of the linear relationships between variables. Multiple linear regression analysis was conducted to identify the predictors of smartphone addiction and PSQI score. A $p$ value of $<0.05$ was accepted as statistically significant.

\section{RESULTS}

Our study included a total of 362 participants including 242 (66.9\%) women and 120 (33.1\%) men. The mean age of the participants was $24.9 \pm 7.1$ years. 239 of the participants $(66.0 \%)$ were 24 years old or younger, while $123(34.0 \%)$ were 25 years old or older. Among the 362 individuals, $47(13.0 \%)$ were married, while 315 (87.0\%) were not.

The median value of the scores that was obtained from SAS was 79. Based on the SAS median score, the participants were divided into two groups as the low-level smartphone use (SAS score $<79$ ) and the high-level smartphone use (SAS score $>79$ ) groups. The descriptive characteristics of the 
Table 1. Descriptive characteristics of the sociodemographic variables in low-level and high-level smartphone users

\begin{tabular}{|c|c|c|c|}
\hline & $\begin{array}{c}\text { Low-level smartphone } \\
\text { user group } \\
\mathbf{n}=181\end{array}$ & $\begin{array}{c}\text { High-level smartphone } \\
\text { user group } \\
\mathbf{n}=181\end{array}$ & p value \\
\hline Age (years) $($ mean $\pm \mathrm{SD})$ & $27.0 \pm 8.2$ & $22.7 \pm 5.1$ & $<0.001$ \\
\hline \multicolumn{4}{|l|}{ Gender, n (\%) } \\
\hline Male & $54(29.8)$ & $66(36.5)$ & 0.180 \\
\hline Female & $127(70.2)$ & $115(63.5)$ & \\
\hline \multicolumn{4}{|l|}{ Education level, n (\%) } \\
\hline Associate's & $21(11.6)$ & $82(45.3)$ & $<0.001$ \\
\hline Bachelor's & $36(19.9)$ & $33(18.2)$ & \\
\hline Master's & $124(68.5)$ & $66(36.5)$ & \\
\hline \multicolumn{4}{|c|}{ Purpose of smartphone use, $\mathrm{n}(\%)$} \\
\hline Talking & $146(80.7)$ & $139(76.8)$ & 0.369 \\
\hline Message texting & $140(77.3)$ & $144(79.6)$ & 0.609 \\
\hline Social media & $130(71.8)$ & $167(92.3)$ & $<0.001$ \\
\hline Mobile applications & $75(41.4)$ & $101(55.8)$ & 0.006 \\
\hline Online gaming & $40(22.1)$ & $65(35.9)$ & 0.004 \\
\hline \multicolumn{4}{|c|}{ Frequency of checking smartphone, $\mathrm{n}(\%)$} \\
\hline $10-19$ & $66(36.6)$ & $20(11.0)$ & $<0.001$ \\
\hline $20-29$ & $46(25.6)$ & $38(21.0)$ & \\
\hline $30-39$ & $34(18.9)$ & $43(23.8)$ & \\
\hline 40 and higher & $34(18.9)$ & $80(44.2)$ & \\
\hline \multicolumn{4}{|l|}{ Keeping the smartphone in bed } \\
\hline Yes & $142(78.5)$ & $165(91.2)$ & 0.001 \\
\hline No & $39(21.5)$ & $16(8.8)$ & \\
\hline
\end{tabular}

sociodemographic variables of the two groups are given in Table 1. The mean age of the high-level smartphone use group $(22.7 \pm 5.1)$ was significantly younger than that of the low-level smartphone use group $(27.0 \pm 8.2)(p<0.001)$. There was no significant difference between two groups regarding distributions of gender $(p=0.180)$. With regard to the education levels, the ratio of the associate's degree students among the high-level smartphone use group was significantly high $(p<0.001)$. The participants in the high-level smartphone use group stated that they used their smartphones significantly more frequently for social media $(p<0.001)$ mobile applications $(p=$ $0.006)$ and playing games $(p=0.004)$ in comparison to the low-level smartphone use group. When the participants were compared based on their frequencies of checking their smartphones, the ratio of those who checked their smartphones 40 or more times a day was significantly higher in the high-level use group $(p<$ $0.001)$. In the same group, the share of those who kept their smartphones with them before going to be was also significantly high $(p=0.001)$.

In the high-level smartphone use group, general sleep quality was lower, sleep latency was longer, scores of sleep disorder and daytime dysfunction were higher as measured by PSQI and the BSI scores were higher. It was found that the high-level smartphone use group had significantly higher values in comparison to the low-level smartphone use group regarding their ESS scores, PSQI total scores, PSQI subscale scores 
Table 2. Comparison of the scale scores in low-level nd high-level smartphone user groups

\begin{tabular}{lccc}
\hline & $\begin{array}{c}\text { Low-level smartphone } \\
\text { user group } \\
\mathbf{n}=\mathbf{1 8 1}\end{array}$ & $\begin{array}{c}\text { High-level smartphone } \\
\text { user group } \\
\mathbf{n = 1 8 1}\end{array}$ & p value \\
\hline Epworth sleepiness scale & $14(11-17)$ & $17(13-20)$ & $<\mathbf{0 . 0 0 1}$ \\
Pittsburgh sleep quality index & $11(7.5-16)$ & $15(12-21)$ & $<\mathbf{0 . 0 0 1}$ \\
Subjective sleep quality subscale & $1(1-1)$ & $1(1-2)$ & $<\mathbf{0 . 0 0 1}$ \\
Sleep latency subscale & $1(0-2)$ & $1(1-2)$ & $<\mathbf{0 . 0 0 1}$ \\
Sleep duration subscale & $0(0-1)$ & $0(0-1)$ & 0.802 \\
Habitual sleep efficiency subscale & $3(2-3)$ & $3(3-3)$ & 0.254 \\
Sleep disorder subscale & $5(2-8)$ & $8(5-11)$ & $<\mathbf{0 . 0 0 1}$ \\
Sleeping pill use subscale & $0(0-0)$ & $0(0-0)$ & 0.071 \\
Daytime dysfunction subscale & $1(0-2)$ & $2(1-3)$ & $<\mathbf{0 . 0 0 1}$ \\
Brief Symptom Inventory & $67(58.5-91)$ & $94(70.5-120)$ & $<\mathbf{0 . 0 0 1}$ \\
Anxiety subscale & $16(13-21)$ & $21(17-28)$ & $<\mathbf{0 . 0 0 1}$ \\
Depression subscale & $16(13-23)$ & $23(17-32)$ & $<\mathbf{0 . 0 0 1}$ \\
Negative self subscale & $15(12-20)$ & $20(16-26)$ & $<\mathbf{0 . 0 0 1}$ \\
Somatization subscale & $11(9-15)$ & $16(12-21)$ & $<\mathbf{0 . 0 0 1}$ \\
Hostility subscale & $9(7-14)$ & $14(9.5-19)$ & $<\mathbf{0 . 0 0 1}$ \\
\hline
\end{tabular}

Table 3. Correlations between SAS score and the variables

\begin{tabular}{|c|c|c|}
\hline & \multicolumn{2}{|c|}{ SAS } \\
\hline & $\mathbf{r}_{\mathrm{s}}$ & p value \\
\hline Age & -0.342 & $<0.001$ \\
\hline Epworth sleepiness scale & 0.314 & $<0.001$ \\
\hline Pittsburgh sleep quality index & 0.385 & $<0.001$ \\
\hline Subjective sleep quality subscale & 0.245 & $<0.001$ \\
\hline Sleep latency subscale & 0.246 & $<0.001$ \\
\hline Sleep duration subscale & 0.011 & 0.841 \\
\hline Habitual sleep efficiency subscale & 0.134 & 0.011 \\
\hline Sleep disorder subscale & 0.362 & $<0.001$ \\
\hline Sleeping pill use subscale & 0.091 & 0.084 \\
\hline Daytime dysfunction subscale & 0.306 & $<0.001$ \\
\hline Brief Symptom Inventory & 0.445 & $<0.001$ \\
\hline Anxiety subscale & 0.413 & $<0.001$ \\
\hline Depression subscale & 0.405 & $<0.001$ \\
\hline Negative self subscale & 0.411 & $<0.001$ \\
\hline Somatization subscale & 0.432 & $<0.001$ \\
\hline Hostility subscale & 0.377 & $<0.001$ \\
\hline
\end{tabular}

SAS $=$ Smartphone Addiction Scale 
Table 4. Linear Regression Analysis Results for SAS

\begin{tabular}{llccccc}
\hline Model & Variables & $\begin{array}{c}\text { Standardized } \\
\text { Coefficients (Beta) }\end{array}$ & $\mathbf{t}$ & $\mathbf{p}$ & $\mathbf{R}^{\mathbf{2}}$ & $\begin{array}{c}\text { Model } \\
\boldsymbol{p} \text { value }\end{array}$ \\
\hline 1 & Somatization subscale & 0.433 & 9.094 & $<0.001$ & 0.185 & $<\mathbf{0 . 0 0 1}$ \\
2 & Somatization subscale & 0.385 & 8.215 & $<0.001$ & 0.239 & $<\mathbf{0 . 0 0 1}$ \\
\hline & Age & -0.242 & -5.158 & $<0.001$ & & \\
\hline
\end{tabular}

SAS $=$ Smartphone Addiction Scale

of subjective sleep quality, sleep latency, sleep disorder, daytime dysfunction, BSI total scores and scores of all subscales of BSI $(p<0.001$, Table 2$)$.

SAS score was significantly and positively correlated with age and negatively correlated with the scores of ESS, PSQI total, PSQI subscales of subjective sleep quality, sleep latency, habitual sleep efficiency, sleep disorder and daytime dysfunction, BSI total, BSI subscales of anxiety, depression, negative self, somatization and hostility. Table 3 shows the correlations between SAS scores and the scores of other scales.

A linear regression analysis was carried out to find the variables that predicted SAS scores. It was found that the BSI subscale of somatization and age predicted SAS scores to a significant extent (Table 4). According to the linear regression analysis, the significant predictors of PSQI scores were the BSI subscales of somatization and depression, SAS scores and age (Table 5).

\section{DISCUSSION}

This study investigated the smartphone use behaviors of 362 students who were enrolled at a

Table 5. Linear Regression Analyses Results for PSQI

\begin{tabular}{llccccc}
\hline Model & Variables & $\begin{array}{c}\text { Standardized } \\
\text { Coefficients (Beta) }\end{array}$ & t & $\boldsymbol{p}$ & R2 & $\begin{array}{c}\text { Model } \\
\boldsymbol{p} \text { value }\end{array}$ \\
\hline 1 & Somatization subscale & 0.659 & 16.587 & $<0.001$ & 0.432 & $<0.001$ \\
2 & Somatization subscale & 0.453 & 7.418 & $<0.001$ & 0.459 & $<0.001$ \\
\hline & Depression subscale & 0.266 & 4.346 & $<0.001$ & & \\
3 & Somatization subscale & 0.414 & 6.669 & $<0.001$ & 0.470 & $<0.001$ \\
& Depression subscale & 0.248 & 4.079 & 0.001 & & \\
& SAS & 0.123 & 2.867 & 0.004 & & \\
& Somatization subscale & 0.405 & 6.591 & $<0.001$ & 0.480 & $<0.001$ \\
& Depression subscale & 0.271 & 4.460 & $<0.001$ & & \\
& SAS & 0.154 & 3.526 & $<0.001$ & & \\
\hline & Age & 0.116 & 2.871 & 0.004 & & \\
\hline
\end{tabular}

PSQI = Pittsburgh Sleep Quality Index

foundation university and the effects of these on different aspects of sleep and psychiatric symptoms. As a result of the study, it was observed that, as smartphone use increased and became problematic, sleep quality decreased, and daytime dysfunction and psychiatric symptoms increased. SAS scores were positively correlated with both PSQI and ESS scores. SAS score was found as a predictor of PSQI scores in the regression analysis. The findings that were obtained here were in agreement with the literature which suggested that problematic smartphone use behaviors have negative effects on the quality of sleep. 
Development of decision-making skills is dependent on the changes the brain experiences throughout life. Insufficiency of decision-making skills increases the tendency towards abuse of any substance. The changes that the brain experiences in adolescence increase impulsivity, and therefore, sensitivity about substance abuse [29]. With the transition to adulthood, de- creases in neuroticism and impulsive behaviors reduces substance abuse problems [30]. In parallel to this information, studies that have been conducted so far found that problematic smartphone use is inversely proportionate to age. We also observed that, as age decreased, smartphone usage became significantly more problematic, and age predicted SAS scores. Individual and social responsibilities and liabilities that increase with age may also contribute to the reduction of time that is spent on smartphone. We found that the associate's degree students have significantly higher problematic smartphone use in comparison to the bachelor's and master's degree students. The younger age of associate's students might explain this finding. The course loads and academic responsibilities of associate's degree students are lighter, and they may have a tendency to spend more time using smartphones.

In previous research, some researchers suggested that, the addiction develops to the social media applications and games provided by smartphones, instead of the phone itself [2]. Likewise, in our study, the high-level smartphone use group used their smartphones significantly more for social media, gaming and other mobile applications in comparison to the low-level smartphone use group. Engaging with social media is one of the significant factors that disrupt sleep. An epidemiological study that was conducted in the USA used online questionnaires to investigate the relationship between social media usage and sleep disorders among 1788 individuals with the age range of 19-32 [31]. The median social media use duration of the sample was found as 61 minutes, and more than half of the sample had moderate or severe sleep disorders. A directly proportional relationship was found between social media use and sleep disorders. The reason for the relationship between problematic smartphone use and sleep disorders in our study could be the need for connecting to social media. Future studies should particularly and distinctively investigate the relationship between using social media via smartphones and sleep disorders.

Previous studies suggested that compulsively looking at one's smartphone may be a part or promoter of problematic behavior. The results of our study supported this issue. SAS scores increased as the frequencies of checking smartphones increased. The behavior of checking increases the mental attachment with the smartphone. Levenson et al. [31] found a relationship between sleep disorders and frequency of visiting social media, rather than the time spent on social media. They argued that this may be an obsessive checking behavior [31].

The dimensions of smartphones make them easier to use practically in every form of posture including lying down and almost everywhere, especially in bed, and development of sleep disorders may be easier. Using smartphones before sleep may also make it difficult to fall asleep by causing cognitive, emotional and physiological arousal [32]. Sleep quality may be disrupted due to the electromagnetic field created by smartphones and reduced secretion of melatonin [3335]. The blue-purple light emitted by the backlight of smartphone screens may delay the time of falling asleep by disrupting the circadian rhythm [36-39]. Telzer et al. [35] reported that, as a result of insufficient sleep in smartphone users, processing decreased in the dorsolateral prefrontal cortex, and the connection between the ventral striatum and insula was reduced during reward processing. In other words, lack of sufficient sleep may be leading to increased usage of smartphones by disrupting impulse control skills [35].

A study that was conducted with 844 Flemish adults at the ages of 18 to 94 revealed that six in every 10 people took their phone with them to the bedroom [40]. As the rate of messaging and making phone calls in bed increased, sleep quality had a tendency to decrease. It was reported that spending time with smartphones in bed increased sleep latency, worsened sleep efficiency, delayed the time of waking up in the morning, increased insomnia scores and daytime fatigue. Our study also showed that those who kept their smartphones with them before sleep had lower sleep quality and higher daytime dysfunction levels. A study by Gradisar et al. [41] in the USA reported that more than half of people who use their phones 
before falling asleep left their phone on, and because of this, they woke up with the incoming notification and found it difficult to fall asleep again [41]. Adams and Kisler [42] stated that $47 \%$ of university students woke up at night to answer messages, while $40 \%$ woke up at night to respond to calls [42]. Rosen's study [43] reported that most students woke up to check their messages, and a third of the sample had short sleep durations.

Presence of psychiatric symptoms may lead to problematic smartphone use or continuation of existing problematic use. In some cases, problematic smartphone use may lead to development of psychiatric symptoms. Additionally, both the presence of psychiatric symptoms and problematic smartphone use may increase tendencies towards each other. Consequently, an underlying genetic or environmental risk may lead to the development of both psychiatric symptoms and problematic smartphone use. In our study, there was a positive correlation with SAS scores and all subscales of BSI, and the BSI subscale of somatization predicted SAS scores. Yen et al. [44] found the scores of the BSI subscales of hostility, depression and somatization higher among teenagers with substance abuse problems. The same study observed that teenagers who had internet addiction had higher BSI hostility, depression and phobic anxiety scores. In a logistic regression analysis, internet addiction was found to be related to hostility, depression and substance abuse disorders [44].

Somatization represents the form of expression of psychological problems especially in underdeveloped societies, and it frequently accompanies depression and anxiety disorders [45]. Somatization is used to express problems of psychological origin more in people with insufficient problem-solving skills and lack of psychological mindedness [46]. If the smartphone is used for coping with psychiatric problems, presence of somatization in these individuals may be understandable.

Excessive use of smartphones may lead to serious deformations in the anatomic stance of the body and various musculoskeletal system symptoms such as pain in the wrists or the neck may develop [1]. The constant position of the head in an angle and fixed position of the arms may lead to contraction of muscles and show an effect that reduces relaxation by lack of antagonistic motion. Smartphone use may lead to damage in the cervical vertebrae [47], a sedentary lifestyle, and as a result of this, feelings of low energy and physiological problems may ensue [48]. In our study, the orthopedic problems caused by smartphones may have increased the BSI somatization scores by increasing somatic complaints. However, we have not addressed this question in the study. Xie et al. [49] showed a relationship between excessive smartphone use and physical symptoms in teenagers. This relationship was mediated by sleep quality [49]. Future studies may investigate the effects of musculoskeletal symptoms that develop as a result of smartphone usage on sleep quality.

While sleep disorders are among the symptoms of depression, depression may also develop in relation to sleep disorders. Smartphone use may have an effect on both sleep and mood. The person may be spending time with their smartphone because they have trouble sleeping, which in turn increases sleep latency and develops smartphone addiction. Having to sleep late and wake up early may increase somatic and depressive complaints such as concentration problems, irritability, fatigue, reluctance towards physical or social activities, headache or diffuse bodily pain due to sleep deprivation. Similarly, if the person spends time with their smartphone to improve the depressive mood, this may not only turn smartphone use problematic and develop sleep disorder. Therefore, there is not a one-way, but a two-way relationship here. A study in Nepal that was carried out with 937 university students at 27 different campuses stated that the state of being addicted to the internet mediated $16.5 \%$ of the indirect effects of sleep quality on depressive symptoms, while sleep quality mediated $30.9 \%$ of the indirect effects of internet addiction on depressive symptoms [50]. Some people use social media to fall asleep, but as a result of this strategy, sleep durations get shorter and daytime dysfunction increases [51]. A longitudinal study that was carried out with university students for 3 years found that presence of sleep disorders predicted usage of online social media and other media tools such as television. It was stated that spending time on social media was a result of sleep disorders [52].

The fact that all the scales that were used in the study were self-report increased the probability of bias. Future studies may obtain more qualified data regarding the characteristics of sleep, based on long- 
term data records by using actigraphy and sleep diaries. Selection of the sample from only amongst foundation university students prevents us from generalization of the findings to all university students or the entire society. The period when the questionnaire forms were distributed to the students corresponded to the period of their mid-term exams. Mid-term periods are when students stay awake for long times to study, their hours of falling asleep become irregular, and therefore, sleep quality decreases, and daytime dysfunction decreases. Collection of the data in the mid-term period may have been the reason for the finding of dis- rupted sleep quality. Repeating the study at the beginning of the term when students have more regular sleep may increase the quality of data.

BSI, which is used to measure psychiatric symptoms, is not sufficient to make a clinical diagnosis, and it uses a limited number of psychiatric symptoms in screening. Psychiatric syndromes should be diagnosed by standardized and structured clinical interviews, and accordingly, it may be recommended to differentiate whether sleep disorders are caused by problematic smartphone use or a psychiatric syndrome.

\section{CONCLUSION}

This study shows that the relationship between problematic smartphone use and decreased sleep quality and increased psychiatric symptomatology in university students is still an important public health issue. Responsible and mindfull use of smartphones by the students throughout the day may provide a positive effect on their sleep. Prohibiting students from using phones may increase their anxiety due to nomophobia, and because of this, they may be encouraged to turn off their phones during classes as a form of a technology break instead of prohibition. Collaboration of physicians that provide public health services, educators and institutions that provide preventive mental health services will be beneficial for informing students about the relationship between sleep disorders and smartphone using styles and developing healthy smartphone usage skills.

Ethics

The study was approved by the Ethics Committee of the university and complies with the Declaration of Helsinki. All subjects were informed about the study and all provided informed consent.

\section{Authors'contribution}

EEY planned the study and collected the data. BÖÜ did the statistical analysis and wrote the manuscript.

\section{Conflict of interest}

The authors disclosed no conflict of interest during the preparation or publication of this manuscript.

\section{Financing}

The authors disclosed that they did not receive any grant during conduction or writing of this study.

\section{REFERENCES}

1. Kwon M, Lee JY, Won WY, Park JW, Min JA, Hahn C, et al. Development and validation of a smartphone addiction scale (SAS). PLoS One 2013;8:e56936.

2. Kuss DJ, Kanjo E, Crook-Rumsey M, Kibowski F, Wang GY, Sumich A. Problematic mobile phone use and addiction across generations: the roles of psychopathological symptoms and smartphone use. J Technol Behav Sci 2018;3:141-9.

3. Panova T, Carbonell X. Is smartphone addiction really an addiction? J Behav Addict 2018;7:252-9.

4. Serino S, Cipresso P, Gaggioli A, Pallavicini F, Cipress S, Campanaro D, et al. [Smartphone for self-management of psychological stress: a preliminary evaluation of positive technology app]. Revista de Psicopatología y Psicología Clínica 2015;19:253-60. [Article in Spain]

5. Toda M, Ezoe S, Takeshita T. Mobile phone use and stresscoping strategies of medical students. Int J Cyber Behav Psychol Learn 2014;4:41-6.

6. Vahedi Z, Saiphoo A. The association between smartphone use, stress, and anxiety: a meta-analytic review. Stress Health 2018;34:347-58.

7. Buysse DJ. Sleep health: can we define it? Does it matter? Sleep 2014;37:9-17.

8. Harvey AG, Stinson K, Whitaker KL, Moskovitz D, Virk H. The subjective meaning of sleep quality: a comparison of individuals with and without insomnia. Sleep 2008;31:383-93.

9. Medic G, Wille M, Hemels ME. Short- and long-term health consequences of sleep disruption. Nat Sci Sleep 2017;9:151-61. 10. Van Cauter E, Spiegel K, Tasali E, Leproult R. Metabolic consequences of sleep and sleep loss. Sleep Med 2008;9:S23-8. 11. Bouloukaki I, Stathakis G, Koloi A, Bakiri E, Moudatsaki M, Pouladaki E, et al. Prevalence and risk factors of poor sleep quality and fatigue during exam periods in university students. ERJ Open Res 2017;3:P2. 
12. Demirci K, Akgonul M, Akpinar A. Relationship of smartphone use severity with sleep quality, depression, and anxiety in university students. J Behav Addict 2015;4:85-92.

13. Hershner S CR. Causes and consequences of sleepiness among college students. Nat Sci Sleep 2014;6:73-84.

14. Mohammadbeigi A, Absari R, Valizadeh F, Saadati M, Sharifimoghadam S, Ahmadi A, et al. Sleep quality in medical students; the impact of over-use of mobile cell-phone and social networks. J Res Health Sci 2016;16-46-50.

15. Lemola S, Perkinson-Gloor N, Brand S, Dewald-Kaufmann JF, Grob A. Adolescents' electronic media use at night, sleep disturbance, and depressive symptoms in the smartphone age. J Youth Adolesc 2015;44:405-18.

16. Matar Boumosleh J, Jaalouk D. Depression, anxiety, and smartphone addiction in university students - A cross sectional study. PloS One 2017;12:e0182239.

17. Tao S, Wu X, Zhang Y, Zhang S, Tong S, Tao F. Effects of sleep quality on the association between problematic mobile phone use and mental health symptoms in Chinese college students. Int J Environ Res Public Health 2017;14:185.

18. Monma T, Ando A, Asanuma T, Yoshitake Y, Yoshida G, Miyazawa T, et al. Sleep disorder risk factors among student athletes. Sleep Med 2018;44:76-81.

19. Lanaj K, Johnson RE, Barnes CM. Beginning the workday yet already depleted? Consequences of late-night smartphone use and sleep. Organ Behav Hum Decis Process 2014;124:11-23.

20. Thomée S, Härenstam A, Hagberg M. Mobile phone use and stress, sleep disturbances, and symptoms of depression among young adults--a prospective cohort study. BMC public health 2011;11:66.

21. Schweizer A, Berchtold A, Barrense-Dias Y, Akre C, Suris JC. Adolescents with a smartphone sleep less than their peers. Eur J Pediatr 2017;176:131-6.

22. Demirci K, Orhan H, Demirdas A, Akpinar A, Sert H. [Validity and reliability of the Turkish version of the smartphone addiction scale in a younger population]. Klinik Psikofarmakoloji Bülteni 2014;24:226-34. [Article in Turkish]

23. Buysse DJ, Reynolds CF, Monk TH, Berman SR, Kupfer DJ. The Pittsburgh sleep quality index: a new instrument for psychiatric practice and research. Psychiatry Res 1989;28:193213.

24. Ağargün MY, Kara H, Anlar Ö. [The validity and reliability of the Pittsburgh sleep quality index]. Türk Psikiyatri Dergisi 1996;7:107-11. [Article in Turkish]

25. Johns M. A new method for measuring daytime sleepiness: the Epworth sleepiness scale. Sleep 1991;14:540-5.

26. Izci B, Ardic S, Firat H, Sahin A, Altinors M, Karacan I. Reliability and validity studies of the Turkish version of the Epworth Sleepiness Scale. Sleep Breath 2008;12:161-8.

27. Derogatis LR. The Brief Symptom Inventory (BSI) : administration, scoring \& procedures manual-II. 2nd ed: [Towson, Md.] : Clinical Psychometric Research; 1992: 55.

28. Şahin NH, Durak A. [A study of the Brief Symptom Inventory in Turkish Youth]. Türk Psikoloji Dergisi 1994;9:44-56. [Article in Turkish]

29. Crone EA, Dahl RE. Understanding adolescence as a period of social-affective engagement and goal flexibility. Nat Rev
Neurosci 2012;13:636.

30. Argyriou E, Um M, Carron C, Cyders MA. Age and impulsive behavior in drug addiction: a review of past research and future directions. Pharmacol Biochem Behav 2018;164:10617.

31. Levenson JC, Shensa A, Sidani JE, Colditz JB, Primack BA. The association between social media use and sleep disturbance among young adults. Prev med 2016;85:36-41.

32. Ivarsson M, Anderson M, Åkerstedt T, Lindblad F. Playing a violent television game affects heart rate variability. Acta Paediatr 2009;98:166-72.

33. Canan F, Yildirim O, Sinani G, Ozturk O, Ustunel TY, Ataoglu A. Internet addiction and sleep disturbance symptoms among Turkish high school students. Sleep Biol Rhythms 2013;11:210-3.

34. Shrivastava A, Saxena Y. Effect of mobile usage on serum melatonin levels among medical students. Indian J Physiol Pharmacol 2014;58:395-9.

35. Telzer EH, Fuligni AJ, Lieberman MD, Galván A. The effects of poor quality sleep on brain function and risk taking in adolescence. NeuroImage 2013;71:275-83.

36. Chang A-M, Aeschbach D, Duffy JF, Czeisler CA. Evening use of light-emitting eReaders negatively affects sleep, circadian timing, and next-morning alertness. Proc Natl Acad Sci U S A 2015;112:1232-7.

37. Li S, Jin X, Wu S, Jiang F, Yan C, Shen X. The impact of media use on sleep patterns and sleep disorders among schoolaged children in China. Sleep 2007;30:361-7.

38. Heo Y, Lee K. Smartphone addiction and school life adjustment among high school students: the mediating effect of self-control. J Psychosoc Nurs Ment Health Serv 2018;56:28-36. 39. Wood B, Rea MS, Plitnick B, Figueiro MG. Light level and duration of exposure determine the impact of self-luminous tablets on melatonin suppression. Appl Ergon 2013;44:237-40.

40. Exelmans L, Van den Bulck J. Bedtime mobile phone use and sleep in adults. Soc Sci Med 2016;148:93-101.

41. Gradisar M, Gardner G, Dohnt H. Recent worldwide sleep patterns and problems during adolescence: A review and metaanalysis of age, region, and sleep. Sleep Med 2011;12:110-8.

42. Adams SK, Kisler TS. Sleep quality as a mediator between technology-related sleep quality, depression, and anxiety. Cyberpsychol Behav Soc Netw 2013;16:25-30.

43. Rosen L, Carrier LM, Miller A, Rokkum J, Ruiz A. Sleeping with technology: cognitive, affective, and technology usage predictors of sleep problems among college students. Sleep Health 2016;2:49-56.

44. Yen J-Y, Ko C-H, Yen C-F, Chen S-H, Chung W-L, Chen CC. Psychiatric symptoms in adolescents with Internet addiction: comparison with substance use. Psychiatry Clin Neurosci 2008;62:9-16.

45. Özen EM, Serhadlı ZNA, Türkcan AS, Ülker GE. Somatization in depression and anxiety disorders. Dusunen Adam 2010;23:60-5.

46. Zhang Haijie ZZ, Zhang Danning. Psychological status and coping strategy of somatization disorders. Int J Clin Exp Med 2016;9:18564-8.

47. Hansraj KK. Assessment of stresses in the cervical spine 
caused by posture and position of the head. Surg Technol Int 2014;25:277-9.

48. Cao H, Sun Y, Wan Y, Hao J, Tao F. Problematic Internet use in Chinese adolescents and its relation to psychosomatic symptoms and life satisfaction. BMC Public Health 2011;11:802. 49. Xie X, Dong Y, Wang J. Sleep quality as a mediator of problematic smartphone use and clinical health symptoms. J Behav Addict 2018;7:466-72.

50. Bhandari PM, Neupane D, Rijal S, Thapa K, Mishra SR,
Poudyal AK. Sleep quality, internet addiction and depressive symptoms among undergraduate students in Nepal. BMC Psychiatry 2017;17:106.

51. Eggermont S, Van den Bulck J. Nodding off or switching off? The use of popular media as a sleep aid in secondary-school children. J Paediatr Child Health 2006;42:428-33.

52. Tavernier R, Willoughby T. Sleep problems: predictor or outcome of media use among emerging adults at university? J Sleep Res 2014;23:389-96. 